\title{
Sobre el proceso de revisión por pares
}

Raúl H Sanchez-Lopez

Editor de AUDITIO

El proceso de revisión por pares es un proceso vital y de gran importancia en una publicación académica. Los artículos que son publicados en un journal o revista científica son evaluados por al menos dos revisores externos. Esta evaluación tiene como misión asegurar que el artículo contenga importantes preguntas científicas, interpretaciones y conclusiones adecuadas y precisas y una metodología bien ejecutada. Citando textualmente las palabras de Kelly et al., (2014): "[...] los artículos que son revisados por pares proporcionan una forma fiable de comunicación científica."

\section{Breve historia}

La revisión por pares se implementó en revistas científicas ya en el siglo XVII. En el siglo XVIII, en journals editados por sociedades se mencionaba que los miembros de la sociedad con interés o experiencia en el tema del que tratara el artículo recibirían el envío para su evaluación y que la identidad de éstos no podría ser desvelada. Esta práctica, también llamada "arbitraje", se implementó en la mayoría de las publicaciones académicas ya en el siglo XIX y se ha mantenido hasta nuestros días. En la actualidad, se está viviendo una nueva revolución en la revisión por pares, intentando hacer el proceso más dinámico y transparente gracias a las nuevas tecnologías. Para una lectura sobre la historia de la revisión por pares recomiendo esta entrada en el blog de F1000Research escrita por Yousuf Al-Mousawi (2020).

\section{El flujo de trabajo de una publicación científica}

Un artículo científico no es cómo un artículo periodístico de los que puedan aparecer en una revista del tipo magazín. El proceso antes de publicar un artículo científico conlleva varios pasos en los que diferentes actores (autores, revisores, editores) se ven involucrados.

Inspirado por el contenido del curso "Cómo convertirse en un editor" del Public Knowledge Project (PKP) School, he adaptado los pasos a seguir al caso concreto de AUDITIO.

1. Proceso de pre-revisión

1.a) El autor prepara y envía el manuscrito.

1.b) El editor jefe se encarga de escanear el envío, asegurar que está completo y que puede ser considerado. Si el manuscrito estuviera 
incompleto, el editor solicitará cambios antes de ser enviado a revisión por pares.

1.c) El editor y equipo editorial evalúan y deciden si el envío puede ser enviado a revisión. Si el tema del envío no entra dentro del enfoque del journal y si o el envío no cumple con las normas para autores, éste podrá ser rechazado.

\section{Proceso de revisión por pares:}

2.a) El editor del artículo (ya sea el editor del journal, editor asociado, o editor invitado) se encarga de supervisar el proceso, escoger e invitar a los revisores y de tomar la decisión final sobre su publicación.

2.b)Los revisores evalúan el manuscrito asegurando su validez científica, coherencia, y legibilidad. Éstos han de completar un informa de evaluación siguiendo las pautas del journal.

2.c) El editor toma la decisión de "aceptar", "rechazar" o "solicitar revisiones".

2.d)En el caso de solicitar revisiones, el editor devuelve el manuscrito a los autores junto con los informes de los revisores.

\section{Revisión y reenvío del manuscrito}

3.a) Los autores tendrán que revisar su manuscrito basándose en los comentarios de los revisores y responder a los comentarios de éstos. Se pueden encontrar ciertas nociones y consejos sobre el estilo y forma de la carta de respuesta en Annesley, T. M. (2011). 3.b) El autor vuelve a enviar el manuscrito, en esta ocasión no cómo un nuevo envío sino como una revisión del envío original.

3.c) El editor deberá comprobar que los comentarios han sido respondidos puntos por punto. El editor podrá entonces tomar la decisión final o realizar una nueva ronda de revisión.

3.d) En caso de enviarlo a revisión, el manuscrito revisado se envía de nuevo a los revisores externos, lo que devuelve el manuscrito al proceso 2 de revisión por pares.

La decisión final del editor o editora será "aceptar" o "rechazar" el manuscrito para publicación. Los procesos 2 y 3 podría repetirse varias veces si el manuscrito requiere de revisiones que no son completamente satisfactorias para que el editor tome la decisión final de aceptar el manuscrito. En algunas ocasiones el/la editor/a puede sugerir que se envíe a otra sección del journal en la que el contenido del artículo podría ser más adecuado.

En AUDITIO, todos los artículos enviados a las secciones de "Artículos de Investigación" y de "Comunicaciones científicas" son revisados por tres revisores, siendo al menos uno de ellos un experto académico sobre el tema y otro de los revisores un profesional de la salud auditiva. El objetivo es asegurar el interés de la contribución para la comunidad científica y clínica y fomentar un estilo adecuado para un público amplio y multidisciplinario. 


\section{Cómo realizar una revisión}

Una revisión es una oportunidad de proporcionar una opinión externa que pueda mejorar el contenido de una publicación científica. Es importante recalcar que la revisión es un proceso confidencial. El contenido del artículo es propiedad intelectual de los autores por lo que no debe ser compartido, teniendo los revisores que mantener su anonimato durante el proceso de revisión tanto de cara a los autores como a terceras personas. Por último, el proceso debe ser riguroso, siendo el/la revisor/a en todo en momento imparcial garantizando que el manuscrito se revise de forma objetiva independientemente de que comparta o no la opinión o conclusiones de los/las autores/as.

En AUDITIO, el informe de revisión comprende tres partes; 1) un resumen de la contribución en palabras del revisor; 2) Comentarios y consideraciones; y 3) Comentarios específicos. La forma de redactar estas partes la he resumido en estas "4Cs" fáciles de recordar:

- Sé constructivo/a: el objetivo de la revisión es mejorar la calidad del manuscrito. Es importante también destacar los puntos fuertes del manuscrito y no solamente basar el informe en puntualizar los puntos a mejorar.

- Sé conciso/a: La revisión debe ser fácil de leer, contener información completa y útil, pero no debe ser innecesariamente extensa.

- Sé claro/a: quizás la más importante de las "4Cs". Claridad no significa sólo concreción, sino también evitar cualquier tipo de ambigüedad. Los autores deben saber exactamente "cómo" pueden mejorar su manuscrito y "dónde" deben enfocar sus esfuerzos durante la revisión.

- Utiliza un lenguaje cortés. Un artículo científico conlleva una gran cantidad de trabajo y comentarios despectivos, sesgados o irónicos no benefician ni al autor ni a la publicación.

Otros journals como PLOS ONE resumen estas normas en lo que "se debe y no se debe hacer". En general, el revisor ha de ser empático y valorar su revisión desde la perspectiva del autor, preguntándose, "¿sería yo capaz de mejorar el manuscrito basándome en estos comentarios?".

\section{AUDITIO, comunicación y pedagogía científica}

En AUDITIO somos conscientes de que muchos de los lectores no están familiarizados con los procesos que hay detrás de las revistas científicas. Sin embargo, creemos que es importante que los socios de la Asociación Española de Audiología participen en este proceso, independientemente de su labor investigadora o su experiencia en el tema en concreto. Es por esto por lo que el equipo editorial estamos disponibles para ayudar a los autores y revisores noveles a contribuir a la vida de la revista científica AUDITIO. Esta editorial, así como futuras comunicaciones, sustentan nuestra misión de hacer pedagogía científica en la amplia y multidisciplinar comunidad audiológica de los hablantes de habla hispana.

Referencias 


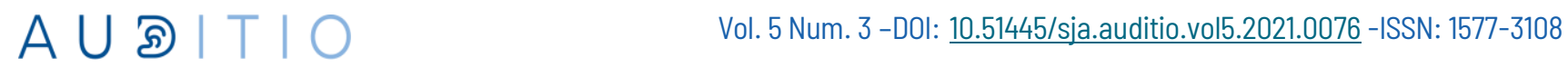

Annesley, T. M. (2011). Top 10 tips for responding to reviewer and editor comments. Clinical Chemistry, 57(4), 551-554. https://doi.org/10.1373/clinchem.2011.162388

SPANISH (translation)

Kelly, J., Sadeghieh, T., \& Adeli, K. (2014). Peer Review in Scientific Publications: Benefits, Critiques, \& A Survival Guide. EJIFCC, 25(3),

227-243.

International Committee of Medical Journal Editors (2019). Recommendations for the Conduct, Reporting, Editing, and Publication of Scholarly Work in Medical Journals. Archivo Disponible en ENGLISH y $\underline{\text { SPANISH. }}$.

PLOS ONE "How to write a peer-review". Internet Archive Link

Yousuf Al-Mousawi (2020) "A brief history of peer-review". F1000

Blog entry Link

Para citar este artículo:

Sanchez-Lopez. R. (2021), Sobre el proceso de revisión por pares vol. 5(2) 37-38.

https://doig.org/10.51445/sja.auditio.vol5.2021.0076

https://journal.auditio.com

Publicado: 31.08 .2021

(c) el Autor. Este artículo está publicado bajo licencia Creative Commons de Atribución 4.0.la cual permite el uso, redistribuición y creación de obras derivadas sin previo permiso.

https://creativecommons.org/licenses/by/4.0/deed.es

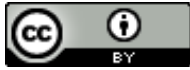

